\title{
CHILDREN WITHIN THE JUVENILE JUSTICE SYSTEM IN NIGERIA: PSYCHOPATHOLOGY AND PSYCHOSOCIAL NEEDS
}

\author{
T.T. Bella ${ }^{1}$, O. Atilola ${ }^{1}$, and O.O.Omigbodun ${ }^{1,2}$ \\ ${ }^{1}$ Department of Psychiatry, University College Hospital, Ibadan \\ ${ }^{2}$ Department of Psychiatry, College of Medicine, University of Ibadan, Ibadan.
}

\author{
Correspondence \\ Dr. Bella TT \\ Department of Psychiatry, \\ University College Hospital, \\ Ibadan. \\ E-mail:bellatt2002@yahoo.com \\ Phone: +234-8025905241
}

\begin{abstract}
Background: Many children in Nigeria face a life of poverty, family instability, inadequate educational opportunities and poor physical and mental health which hinder their ability to develop into healthy adults, live an improved quality of life or fulfil their life aspirations. These factors have also been associated with juvenile delinquency and need for institutional care.

Objectives: As a step toward providing comprehensive services for incarcerated children in Nigeria, this study aimed to identify the psychosocial needs as well as types of psychopathology among a group of incarcerated children at the Ibadan remand home.

Methods: A cross-sectional survey of children and adolescents at the Ibadan remand home was carried out using a semi-structured questionnaire.

Results: A total of 59 children were assessed over a one year period. Majority $(90 \%)$ were in need of care and protection. All $(100 \%)$ had significant psychosocial needs presenting as difficulty with their primary support, economic, social environment, or educational systems. Majority (97\%) also demonstrated significant psychopathology and anxiety, suicidal and depressive symptoms were the most commonly elicited.

Conclusions: Incarcerated children in this study showed significant mental health needs which need to be addressed as a matter of urgency. This should be carried out through the collaborative efforts of mental health professionals with various stakeholders in child care.
\end{abstract}

Keywords: Children, Psychopathology, Psychosocial, Nigeria, Juvenile

\section{INTRODUCTION}

Nigeria is the most populous sub-Saharan country with a predominantly youthful population of less than 15 years of age ${ }^{1}$. However, many of its children face a life of inadequate educational opportunities, poor physical and mental health ${ }^{2}$. Inspite of the enormous natural endowment of the country, development has been slow due to poor public management, and serious crisis of governance resulting in decaying infrastructure, stagnant economy, corruption and widespread poverty. ${ }^{3}$ A life of want, family instability, exposure to physical, sexual and emotional abuse has been associated with delinquent behaviour among children, and so a large number of Nigerian children are expected to be involved with the juvenile justice system. ${ }^{4,5}$

The Children and Young Persons Act II is the major piece of legislation dealing with matters affecting children and young persons in Nigeria. ${ }^{6}$ Its stated pur- pose is "to make provision for the welfare of the young, and the treatment of young offenders and for the establishment of juvenile courts'. ${ }^{6}$ Under the terms of the children and young persons law (CYPL), there are three categories of children who may become involved with the juvenile justice system: children in conflict with the law (those who have committed crimes similar to adult crimes), children in need of care and protection (those who have been abandoned or left destitute by their parents, or children of criminals, beggars or destitutes), and children beyond parental control (those brought to the attention of the authorities by their parents and are alleged to have engaged in minor criminal activity as well as truancy and running away from home). ${ }^{7}$

Institutional care for juveniles in Nigeria could be in remand homes, approved schools or borstal institutions. Remand homes serve as detention/ custody sites (maximum of 3 months) for juveniles awaiting trial, 
or disposal after a guilty verdict. Children in need of care and protection and children beyond parental control are also commonly kept in the remand home while a social inquiry report is being prepared. Approved schools are more permanent educational facilities for children in contact with juvenile justice where they are placed for at least 3 years, while Borstal institutions are specifically designated for the institutionalization of offenders and other categories of children between the ages of 16-21, for a period of about 5 years $^{6}$.

Studies on juvenile justice systems in Nigeria reveal that these facilities were established for the purpose of reformation, rehabilitation and reintegration of juveniles and as such facilities for vocational and formal educational instruction were put in place in order to realize these goals. ${ }^{2}$ These facilities however have undergone a marked deterioration since the 1980's due to lack of proper policy, legal and institutional frameworks, gross under funding, inadequate staff, and lack of necessary training facilities. ${ }^{2}$

Children who enter the Nigerian juvenile justice system usually meet the police as their first point of contact. A study carried out on the treatment of Juveniles during arrest and detention by the police found that about two-thirds $(66.5 \%)$ of the juveniles reported being verbally abused, physically assaulted $(64.7 \%)$, and threatened with beating $(68.5 \%){ }^{2}$ Only $13.7 \%$ reported being well fed in police cells; and $12.9 \%$ were provided with adequate materials for personal hygiene. Within the custodial institutions, the situation was only slightly better with a high proportion of juveniles reporting subjection to mental or psychological torture by threats of beating $(45.9 \%)$, denial of food $(30.0 \%)$ and long detentions $(31.7 \%){ }^{2}$

Inspite of these reports, little attention had been paid to the psychological well being and eventual outcome of these children till date and they often lack access to mental health care. ${ }^{2}$ Moreover, recent studies suggest that about two thirds of youths involved with the juvenile justice system meet criteria for one or more psychiatric disorders, even after excluding conduct disorder. ${ }^{8,9}$ As an important step towards planning and providing mental health services for these children in Nigeria, the mental health needs of children and adolescents in a remand home facility in South West Nigeria were determined.

\section{METHODS}

\section{Study site}

This study was carried out in Ibadan, the largest traditional urban centre in Africa with an estimated population of two million. ${ }^{10}$ The Ibadan remand home is the only juvenile correctional facility located in the city and was established by the state government in 1955 . It is located on an expanse of about four acres with one dormitory which is partitioned for males and females, a central administrative area which is attached to another building currently being renovated for use as a classroom, and 2 other bungalows that serve as living quarters for some of the staff members. The staff strength is made up of three wardens who are also social workers, 2 part time nurses and 3 supporting staff (one caterer, and two night guards). Meagre health services are provided by the nurses who work few hours between $8-4$ pm on weekdays only. There is no provision for emergency services and the home lacks even a first-aid box.

\section{Instruments}

\section{A Sociodemographic Questionnaire}

This obtained information on child's age, gender, school and class, religion, family type, occupation and marital status of the parents, present abode, and the reason for admission into the home.

\section{A semi- structured interview Guide}

This was modified from the Kiddie - SADs which is diagnostic interview designed to assess current and past episodes of psychopathology in children and adolescents according to DSM-III-R and DSM-IV criteria.

\section{Procedure}

This study was part of a mental health programme organized in partnership with a faith based organization to provide mental health services to children in this facility. Approval for the programme was granted by the Oyo state Ministry of women affairs, community development and social welfare. Visits were made on a monthly basis and all children living in the home at the first visit, plus new admissions over a one year period were interviewed. Parental consent was waived in accordance with the practice in other parts of the world in view of the difficulties envisaged in tracing the parents ${ }^{11}$. However, individual consent was obtained from children above the age of 13 years. Participants were administered face-to-face interviews in a private area of the facility. All interviews were conducted by trained clinicians and lasted approximately 30-40 minutes.

\section{Data Analysis}

Data analysis was done using the Statistical Package for Social Sciences version 15.0 (SPSS 15). Descriptive statistics such as means and standard deviations, were used to summarize continuous variables, while categorical variables were summarized with percentages. The chi-squared test was used to compare two proportions and to investigate the association between two qualitative variables at the $5 \%$ level of significance. 


\section{RESULTS}

\section{Sociodemographic Data}

A total of 59 children were assessed over a 12 month period; $(60 \%)$ males and $40 \%$ females. The mean age of the children was 11.68 years (SD:4.8). During the period of the study, $51(90 \%)$ children were categorized as in need of care or protection, $2(3 \%)$ were in the home because of juvenile offences (stealing) while $4(7 \%)$ were beyond parental control. The sociodemographic profile of the inmates is shown in Table 1.

\section{Psychosocial needs}

Significant psychosocial needs were identified in all of the children. 54 children (96\%) had problems with their primary support group before being brought to the remand home evident as separation from parents, family dysfunction/disruption, and abandonment. Seven children $(12 \%)$ had been living on the streets for several months in the last one year before incarceration.
In addition, $9(15.2 \%)$ reported physical abuse before incarceration from caregivers, while $2(3.5 \%)$ reported sexual abuse. All who reported sexual abuse were females. 26(45\%) were not attending school at the time of being brought to the home and none had gone beyond secondary school education. Only $5(8 \%)$ of the children were currently attending school from the remand home, even though majority of them had been living there for over a year.

\section{Psychopathology}

At the initial assessments, psychopathology was identified in $55(97 \%)$ of the children (Table 2). Anxious preoccupations and depressive symptomatology were the most common psychopathologies identified. Depressive symptoms (21.9\% vs $17.9 \%)$, suicidal ideation $(28 \%$ vs $21.4 \%)$ and attempts $(12.5 \%$ vs $7.1 \%)$ were higher in males than females though not significantly. Suicidal ideations and attempts were significantly associated with depressive symptoms but not with any

\begin{tabular}{|l|l|l|}
\hline Sociodemographic variable & Number & $(\%)$ \\
\hline $\begin{array}{l}\text { Marital Status parents } \\
\text { Married }\end{array}$ & 9 & $(15.5)$ \\
\hline Separated/orphaned & 32 & $(55.1)$ \\
\hline Parents never married & 4 & $(6.8)$ \\
\hline Not known & 14 & $(24.1)$ \\
\hline Fathers occupation & & \\
\hline Unskilled self employed & 8 & $(13.7)$ \\
\hline Semiskilled self employed & 18 & $(31)$ \\
\hline Junior- intermediate civil servant/ company worker & 5 & $(8.5)$ \\
\hline Not Known & 27 & $(46.5)$ \\
\hline Mothers occupation & & \\
\hline Unskilled self employed & 21 & 36.2 \\
\hline Semiskilled self employed & 11 & 18.9 \\
\hline Junior - Intermediate civil servant/ company worker & 8 & 13.6 \\
\hline Not known & 19 & 32.7 \\
\hline Residence before incarceration & & \\
\hline Both parents & 5 & $(8.6)$ \\
\hline Father/ mother alone & 12 & $(20.6)$ \\
\hline One parent and stepparent & 11 & $(18.9)$ \\
\hline Other relatives & 11 & $(18.9)$ \\
\hline Non relations & 6 & $(10.3)$ \\
\hline Not known & 13 & $(22.4)$ \\
\hline Education & & \\
\hline No formal education & 21 & $(36.2)$ \\
\hline$<6$ years of Primary education & 25 & $(43.1)$ \\
\hline$\geq 6$ years education & 8 & $(13.7)$ \\
\hline Vocational training & 1 & $(1.7)$ \\
\hline Not known & 2 & $(3.4)$ \\
\hline
\end{tabular}

Table 1: Sociodemographic characteristics of Remand Home Inmates 
other type of psychopathology. [66.7\% of children with current depressive symptoms also had suicidal ideation $\left(\mathrm{x}^{2}=13.88 \mathrm{p}<0.001\right)$ while $50 \%$ of those with current depressive symptoms had attempted suicide $\left.\left(\mathrm{X}^{2}=26.667, \mathrm{p}<0.001\right)\right]$. Conduct behavioural problems were present in $16.7 \%$ of those with depression.

\begin{tabular}{|l|l|}
\hline Type of Psychopathology & $\begin{array}{l}\text { N=59 } \\
\text { n(\%) }\end{array}$ \\
\hline Anxious preoccupations & $20(33)$ \\
Suicidal thoughts & $15(25.4)$ \\
Depressive symptoms & $12(20.3)$ \\
Learning difficulties & $11(18.6)$ \\
Conduct problems & $11(18.6)$ \\
Hallucinatory experiences & $8(13.5)$ \\
Previous suicidal attempts & $6(10.1)$ \\
Epilepsy & $5(8.4)$ \\
Enuresis & $3(5)$ \\
Substance abuse & $3(5)$ \\
PTSD & $1(1.6)$ \\
Encopresis & $1(1.6)$ \\
PICA & $1(1.6)$ \\
\hline
\end{tabular}

Table 2: Types of Psychopathology in Remand Home Inmates

\section{* Epilepsy included as a type of psychopathology because of the stigma with which it is viewed in the developing world.}

\section{DISCUSSION}

This study shows that majority of the children in the Ibadan remand home have significant problems with their primary support, social and educational systems, as well as emotional, learning and behavioural problems. The first needs assessment carried out in this juvenile facility by Odejide \& Toye in 1976 (30 years ago $)^{12}$ assessed 64 inmates categorized as offenders $(54 \%)$, care or protection $(34 \%)$ and beyond parental control $(7 \%)$ with a male to female ratio of $3.3: 1$. A similar study of 51 juveniles in a borstal remand centre in South West Nigeria found the commonest reason for admission as being beyond parental control $(68.6 \%) .{ }^{13}$ Our present findings suggest that there are now more females involved in the Nigerian juvenile justice system and more children in need of care or protection which is not likely to be due to a decrease in the rate of crime in Nigeria. Possible explanations for this could be the widespread cultural beliefs, which encourage abandonment of children with mental disabilities, congenital abnormalities or epilepsy as our results show that about $10 \%$ of inmates had mental retardation while $8 \%$ suffered from epilepsy. ${ }^{14}$

Another possible explanation for the high rates of children in need of care and protection could be the rapid migration from rural to urban areas which occurred in Nigeria between 1985 and 1993 when about $20 \%$ of the rural poor moved into urban areas which did not have provisions for them. The ensuing poverty and lack of social support may have led to the disintegration of families thus, producing more abandoned children. ${ }^{15}$ In addition, there are also indications that police officers who are usually the first point of contact for children who enter the Nigerian juvenile justice system, often falsify the ages of children in order to pass them off as adults so as to avoid adherence to the complex legal requirements for their disposal. ${ }^{6}$ This may also have pushed more child offenders into the regular adult criminal justice system.

The psychosocial needs of the inmates of the home identified in this study are similar to what was reported by Odejide and Toye (1976), who found that only $31.3 \%$ of children in the home had parents living happily together. The parents of the remaining children either frequently quarrelled were separated/divorced or dead ${ }^{12}$. The situation seems to have deteriorated with only $15 \%$ of parents in this study being married. Likewise, in the 1976 study, less than a third (29.7\%) were attending school and in the present study only about half $(45 \%)$ were attending school before incarceration. Another study which looked at inmates in similar institutions from 15 Nigerian states, also found that only $37.4 \%$ were from monogamous homes, majority of parents (as in the present study) had unskilled or semiskilled jobs and only $41.5 \%$ attended school before incarceration. It is noteworthy, that a significant percentage of children in this study could not give their sociodemographic details. Possible reasons for this could be that some children were too young to remember such information correctly. Others may have been reluctant, fearful or deliberately refused to disclose information that could help in tracing their parents following different forms of abuse ${ }^{3}$. The mental retardation observed in some of the children may also have contributed to this inability.

In recent years, several studies have focused on vulnerable children in Nigeria and these have been classified as orphans and street children. ${ }^{17,18,19} 20$ Apart from similarities in dysfunctional family backgrounds coupled with poverty and poor educational backgrounds, ${ }^{17}$ street children seem slightly different from the children in this study. Firstly, they are older (mean age of 18.4 years vs 11.8 years), have higher rates of substance abuse, $(50-70 \%$ vs $5 \%)$, higher rates of conduct and oppositional problems such as school truancy and suspension, stealing, lying and prostitution (35-50\% vs $18 \%$ ), and very low rates of stay in remand homes $(9.4 \%)$. It is possible then that because these children are older, they are able to avoid the law 
and survive economically on the streets, but there is probably still some overlap between the two groups. Rates of psychopathology among children in the general population worldwide and in Africa have been estimated at $15-20 \% .{ }^{20,21,22}$ Incarcerated youths however are reported to have much higher rates $(66 \%$ $72 \%)^{8}$, probably due to a combination of risk factors such as poor parenting, parental marital failure, violence and low social class which compromise neural functioning needed for normal stress reactivity and self regulation ${ }^{23}$. Maru et al, (2003) ${ }^{24}$ in Nairobi reported the crude psychiatric morbidity (CPM) rate in a Kenya juvenile court as $44.4 \%$ with conduct, mood and hyperkinetic disorders being most common. In this study, the rate was as high as $96.5 \%$. Anxiety and Depressive symptoms which have been reported to be most common among incarcerated youth ${ }^{25}$ were also found to be most common in this study. Though higher rates of psychopathology have been reported among incarcerated female youths as compared to males, ${ }^{25,26}$ this study did not find a statistically significant difference between the sexes. The former studies however were carried out among samples of pure offenders with larger sample sizes, while this study had a more heterogeneous group and very small size. The risk of suicide is reported to be greater in incarcerated youths due to high rates of psychiatric disorder and trauma. Conditions associated with confinement such as separation from loved ones, crowding, sleeping in locked rooms, and solitary confinement further increase the risk for suicide. ${ }^{27,28}$ Suicide ideation was the $2^{\text {nd }}$ most common psychopathology identified in this sample with a prevalence of $25.4 \%$. This doubles the 6 month prevalence rate of $10 \%$ reported by Abram et al, $(2008)^{29}$ among newly detained juveniles in Chicago. However, the lifetime prevalence of previous suicidal attempt (11\%) reported in Abram's study is comparable with ours.

The high rates of psychopathology found among children in this study constitute important preliminary epidemiological data which could serve as a guide for health planners and policy makers. This is based on the fact that in a country like Nigeria where mental health resources are scarce and the limited mental health services are poorly organized ${ }^{30},{ }^{31}$ children in institutions are likely to be last on the allocation list for resources. The major strengths of this study is that it provides preliminary data on the demographic profile, psychosocial needs, and types of psychopathology among incarcerated children in a developing African country in the $21^{\text {st }}$ century. It also identifies them as another sub-group of vulnerable children. The study was however limited by the small sample size, thus making it difficult to generalize the findings.

\section{CONCLUSION}

The findings from this study serve as a renewed call for developing African countries to urgently address the economic and social empowerment of families, eradicate poverty, and provide free, compulsory quality education and health care services for children. Mass public enlightenment programmes in areas such as family values, child discipline and parental skills need to be invested in, and the laws protecting children need to be reviewed and implemented so that children's rights are protected both within the family and whenever they may come into contact with the law.

\section{REFERENCES}

1. Federal Ministry of Health (1996) Health in Nigeria: 1994/95 Health Management Information System, Federal Ministry of Health. Abuja

2. Rights of the Child in Nigeria Report on the implementation of the Convention on the Rights of the Child by Nigeria A report prepared for the Committee on the Rights of the Child 38th Session - Geneva, January 2005

3. Street children and the juvenile justice system in Lagos state of Nigeria, A Nigerian Report. Human Development Initiatives, 2004

4. Oloruntimehin $\mathbf{O}$. The role of family structure in the development of delinquent behaviour among juveniles in Lagos. Nigerian Journal of Economics and Social Sciences 1970:12, 185-203

5. Sakir O., Aydin E., Remzi O., et al. Juvenile delinquency in developing countries. A province example in Turkey. International Journal of Law and Psychiatry 2005; 28 (4)430 -441

6. Nigeria: focus on the administration of juvenile justice. Humanitarian news analysis of the UN office for the coordination of humanitarian affairs. August 2002. Downloaded at www.irinnews.org/reports on 10th August 2009

7. Child and young persons Law (1978), volume 1, chapter 22, Part 2 (3); Part 5, 33(2); Part 5, 34.

8. Teplin L., Abram K., McClelland G., et al. Psychiatric disorders in youth in juvenile detention. Arch Gen Psychiatry 2002; 59:1133-1143

9. Abram K.M., Teplin L.A., Charles D.R., et al. Posttraumatic Stress Disorder and Trauma in Youth in Juvenile Detention. Arch Gen Psychiatry. 2004; 61:403-410 
10. National population commission, 1999

11. Shaffer D. Use of passive consent in child and adolescent mental health research; effects of letter from Dr Charles R. McCarthy, director of the office for protection from research risks, NIH (editorials). Research notes in Child and Adolescent Psychiatry. Summer 1992; 10

12. Odejide A. and Toye S. A survey of the inmates of a remand home in Ibadan. Nigerian journal of pediatrics 3 (2) 521976

13. Ogunlesi A.O. Nigerian juvenile offenders: a case controlled study. Med Law. 1991; 10(4):369-74.

14. Omigbodun O.O. Psychosocial issues in a child and adolescent psychiatric clinic population in Nigeria. Soc Psychiatry Psychiatr Epidemiol. 2004 39 : 667-672

15. UNICEF, 2004

16. Ulzen T. and Hamilton $H$. The nature and characteristics of psychiatry co morbidity in incarcerated adolescents. Canadian Journal of Psychiatry 1998;43: 57-63

17. Olley B.O. Social and health behaviors in youth of the streets of Ibadan, Nigeria. Child Abuse \& Neglect 2006:30; 271-282

18. Aderinto A.A. Social correlates and coping measures of street children: A comparative study of street and non-street children in South-western Nigeria. Child Abuse Neglect, 2000; 24(9), 1199_ 1213

19. Ebigbo P. Street children: The core of and neglect. Africa Insight 1996; 26(3), 244-249.

20. Omigbodun O.O. Psychosocial Attributes of Orphaned Youths in Ibadan Metropolis: Implications for Reproductive Health Trop J Obstet Gynaecol, April 2006;.23 (1)

21. Costello A. Developments in child psychiatric epidemiology. J Am Acad Child Adolesc Psychiatry 1989, 28:836-841
22. Gureje O., Omigbodun O., Gater R.A. et al. Psychiatric disorders in a paediatric primary care clinic. British journal of Psychiatry 1994; 165: 527 $-530$

23. Leslie L.K., Gordon J.N., Lambros K. et al. Addressing the Developmental and Mental Health Needs of Young Children in Foster Care J Dev Behav Pediatr. 2005 April; 26(2): 140-151

24. Maru H.M., Kathuku D.M., and Ndetei D.M. Psychiatry Morbidity among Children and Young Persons appearing in the Nairobi Juvenile Court Kenya. East Afr Med J. 2003 Jun; 80(6):281.

25. Cauffman E. A Statewide Screening of Mental Health Symptoms among Juvenile Offenders in Detention J. Am. Acad. Child Adolesc. Psychiatry 2004;43(4):430-439

26. Espelage D., Cauffman E., Broidy L., et al. Cluster-analytic investigation of MMPI profiles of serious male and female juvenile offenders. J Am Acad Child Adolesc Psychiatry 2003; 42:770-777

27. Parent D.G., Leiter V., Kennedy S., et al. Conditions of Confinement: Juvenile Detention and Corrections Facilities. Washington, DC: Office of Juvenile Justice and Delinquency Prevention, U.S. Department of Justice; 1994.

28. Marcus P. and Alcabes P. Characteristics of suicides by inmates in an urban jail. Hosp. Community Psychiatry. 1993; 44:256- 261

29. Abram K.M., Choe J.Y., Washburn J.J., et al. Suicidal Ideation and Behaviors Among Youths in Juvenile Detention. J. Am. Acad. Child Adolesc. Psychiatry 2008; 47(3):291-300.

30. Okasha A. Mental Health in Africa; the role of the WPA. World Psychiatry 2005;1: 32-35

31. Omigbodun O.O. and Esan O.B. Reasons for Consultation in the Psychiatric Out -patient Clinic of a University Teaching Hospital in Nigeria. Is this an optimal use of psychiatrist's time and expertise? Psychiatric Bulletin 2003; 27, (02) 105: 1-3 